\title{
Terrorismo, Legitimidad y Militancia: Un Análisis Discursivo sobre ETA*
}

\author{
Jerónimo Ríos Sierra \\ Investigador postdoctoral en la Facultad de Ciencias Políticas y Sociología de la Universidad Complutense \\ de Madrid, como beneficiario de las Ayudas de Atracción del Talento Investigador que cofinancia la \\ Comunidad de Madrid (2018). Madrid, España. \\ E-mail: jeronimo.rios@ucm.es
}

\section{INTRODUCCIÓN}

$\mathrm{E}^{\mathrm{I}}$ l siguiente trabajo aborda cómo antiguos integrantes del grupo terrorista Euskadi Ta Askatasuna (ETA) entienden el sentido de la violencia política, tanto desde una mirada retrospectiva como con vistas al futuro. Se trata de conocer la manera en que es percibida por antiguos integrantes de ETA la situación política del País Vasco y su evolución desde el recurso del terrorismo hasta la participación política. Se plantean cuestiones relacionadas con la legitimación de dicho terrorismo o la pérdida de respaldo a partir de mediados de la década de los 1990. Se problematizan los aspectos que, según antiguos miembros de ETA, explican la erosión en el respaldo de la violencia, como la falta de apoyo social $\mathrm{u}$ otros hechos que afectaron el modo cómo se comprendía el terrorismo, tal y como sucedió con los atentados del 11-M. De igual manera, se proponen escenarios futuros sobre cómo interpretar la situación vasca tras el proceso de abandono de las armas, culminado en la primavera de 2018. Con todo esto, es posible observar de qué modo se integra la justificación de la existencia de ETA y se exalta su contribución como factor indisociable desde el cual entender

*Este artículo de investigación es resultado del proyecto 2018-T2/SOC-10508, financiado por la Comunidad de Madrid. Se agradecen los comentarios de Gaizka Fernández Soldevilla, David Mota y Mariano García de las Heras. Igualmente se agradecen las acertadas sugerencias de los evaluadores anónimos del texto. Todos los testimonios y entrevistas recogidas en este trabajo fueron realizadas durante el trabajo de campo compartido junto a Egoitz Gago, entre septiembre y noviembre de 2018.

DADOS, Rio de Janeiro, vol.64 (4): e20190258, 2021

https://doi.org/10.1590/dados.2021.64.4.246 
la fuerza política de la que goza actualmente la izquierda abertzale, a través de la coalición política Euskal Herria Bildu (EH Bildu), en la que se encuentra el partido político afín a ETA: Sortu.

Sobre ETA en general se ha escrito una prolija literatura, la cual integra diferentes miradas, aportes y posiciones. Los primeros trabajos, realizados a finales del franquismo, revelan una posición de mayor militancia, que ubica a ETA como un agente de lucha contra el franquismo (Letamendía, 1975; López Adán, 1976). Sin embargo, a medida que se ha ido desclasificando documentación y se han abierto nuevas vías de investigación, la rigurosidad de los trabajos, especialmente entre científicos sociales y contemporaneístas, ha conferido mayor seriedad a los trabajos sobre ETA. A tal efecto, es indudable que la llegada de la democracia a España destapó de forma evidente y transversal el carácter terrorista de la organización. Así, es a partir de entonces que la sociedad española en general cambió su percepción sobre ETA, tras la consolidación de las medidas de liberalización de la arena política adoptadas a partir de 1978. Existen, al efecto, aportaciones de obligada referencia que abordan sus fundamentos ideológicos (Bruni, 1987; Domínguez, 2000; Bullain, 2011), mitos y símbolos (Casquete, 2009; Fernández Soldevilla, 2014, 2016). Otros plantean miradas históricas más amplias (Letamendía, 1994; Garmendia, 1996; Elorza, 2000; Mees, 2019), mientras que existen, igualmente, aportaciones destacadas centradas en los repertorios de acción y la estrategia de ETA (Ibarra, 1989; Ibarra y Ahedo, 2004; Sánchez-Cuenca, 2011). Finalmente, también existen trabajos "benévolos" con la causa del grupo terrorista y, por ende, más cercanos a lo que podría entenderse como una cierta justificación historiográfica (Egaña, 2017; Egaña y Giacopuzzi, 2012).

Sobre el fin de la violencia de ETA se han publicado numerosos trabajos no académicos, pero no por ello menos relevantes, como los de Domínguez (2012), analizando la asfixia de ETA resultante de la lucha antiterrorista; o los de Rodríguez Aizpeolea (2013) o Izquierdo y Rodríguez Aizpeolea (2017), abordando desde una perspectiva más amplia el fin de ETA como resultado de una derrota proveniente de varios ámbitos. También estaría el libro de Portela (2016), que a modo de ensayo analiza diferentes "memorias íntimas" de la violencia terrorista. Asimismo, desde las ciencias sociales destacan aportaciones para las cuales el fin de ETA, más que a una simple derrota, responde a un proceso de transformación política producto del (nuevo) sujeto político que representa la sociedad vasca y, en especial, la posición abertzale (Zabalo y Saratxo, 
2015; Zulaika y Murua, 2017; Duhart, 2017, 2019). A diferencia de estos, Mahoney (2018) considera clave la escasa audiencia del terrorismo dentro del espacio ideológico y social abertzale, de manera que el fin de ETA sería resultado de un proceso decadente que inicia en 1992, tras el golpe asestado en Bidart ${ }^{1}$. Un momento de inflexión tras el cual, el grupo terrorista, lejos de cualquier atisbo de victoria, radicaliza el cleavage nacional-independentista (García de las Heras, 2018).

En parte por lo anterior, Rivera señala que "cuando ETA anunció su final terrorista no llegó a Euskadi ninguna paz: solo cesó la fuerza distorsionadora que la hacía imposible desde hacía medio siglo" (Rivera, 2018:130). Algunos van más allá, pues si bien ETA fue derrotada por la lucha antiterrorista desarrollada durante la década pasada, niegan esta evidencia, alertando sobre el riesgo de un supuesto falseamiento de la memoria (Alonso, 2018). Esto, en tanto que su principal interés sería "blanquear" el ideario "terrorista" para que tenga cabida en el escenario político vasco. Un aspecto relacionado con el binomio víctimas del terrorismo-memoria que, en cualquier caso, será abordado de manera plural en los años siguientes (Domínguez, 2017; De Pablo, 2017; López Romo, 2018; Jiménez y Marrodán, 2019 o De Pablo, Mota y López de Maturana, 2019).

A pesar de todo, las narrativas y discursos ofrecen una atención minoritaria como objeto de análisis. Aunque el de estudio sobre ETA ha gravitado en la última década desde miradas más propias de la violencia política y el terrorismo, hacia otras más centradas en las víctimas o la memoria, siguen siendo pocos los trabajos que recurren a entrevistas con los actores directamente involucrados en el conflicto vasco. Recientemente, el aporte de Silva, Sánchez y Araluce (2017) integra testimonios de familiares y miembros de la Guardia Civil - que fue el cuerpo más golpeado por ETA. Poniendo la mirada en exintegrantes de ETA, son de obligada referencia los trabajos de Alcedo (1996), Reinares (2011), Fernández Soldevilla (2013) e Iñaki Soto. Este último es especialmente interesante, en tanto que buena parte de los marcos interpretativos que se encontrarán en este trabajo - sobre la necesidad de la violencia política y el terrorismo como recursos, el diagnóstico de un pueblo oprimido por el "Estado español", la necesidad de aspirar a una "liberación nacional" a toda costa, o las trayectorias del uso de la violencia y su justificación - son coincidentes con los relatos de la dirección de ETA, entrevistada poco antes de anunciar su final definitivo, el 3 de mayo de 2018 (Soto, 2018). 
Dicho esto, las siguientes páginas se organizan en cuatro partes diferenciadas. Primero, se presentan los aspectos teóricos y metodológicos que aproximan el trabajo a un ejercicio de análisis discursivo y marcos de interpretación. Tras ello, se muestra la evolución del activismo de ETA, desde los años 1960 y hasta la actualidad. Esto sirve de soporte para entender la estructura discursiva de los entrevistados, que integra miradas a modo de diagnóstico, pronóstico y repertorios de acción, desde las que entender el alcance y significado de la violencia política y el terrorismo en el País Vasco. Finalmente, se presentan conclusiones que invitan a explorar posibles escenarios de investigación, aún hoy en día expeditos y por desarrollar.

\section{METODOLOGÍA: NARRATIVAS Y ENTREVISTAS EN LA INVESTIGACIÓN SOCIAL}

La mirada discursiva permite abordar el sentido de la práctica política y, por extensión, de cuestiones como la violencia política o el terrorismo, para lo cual el empleo de narrativas ha sido recurrente en la investigación social y politológica desde la década de los 1970 del siglo XX. Hacer referencia a narrativas implica analizar elementos que resultan de la experiencia y que, a la vez, construyen el sentido de los acontecimientos. Más allá de un mero análisis semántico, este artículo procura adentrarse en el análisis de los lugares de la enunciación y las estrategias de los actores que emiten el discurso (Prokkola, 2014). Quizá, por lo anterior, en la última década han ganado fuerza los conocidos como memory studies, que se han convertido en una rama autónoma a medio camino entre la historia y las ciencias sociales. De este modo, la metodología utilizada en este trabajo refuerza el posicionamiento cualitativo y permite defender la utilización de fuentes epistemológicas que posibilitan renovar determinados objetos de estudio.

Metodológicamente, las narrativas pueden ser obtenidas de diferentes maneras, aunque en este trabajo se recurre a dos tipos de fuentes. En primer lugar, revisando artículos, conferencias, documentos resultantes de los debates de ETA y una prolija literatura académica. Por otro lado, recurriendo a entrevistas semiestructuradas con miembros destacados de ETA. Sobre estas se propone una mirada a los marcos interpretativos (frame analysis), buscando indagar en su universo textual y la interpretación que realizan de los acontecimientos. Así, se problematiza sobre 
cuestiones como el sentido del terrorismo, los elementos que afectaron su desestimación como repertorio, o la lectura que hacen de la actual situación política del País Vasco.

Como se podrá observar, existe un proceso de identificación abierto con la necesidad de recurrir al terrorismo para satisfacer los objetivos políticos de ETA, aunque este se dota de anclajes sociales, pues el recurso de la violencia responde en última instancia a elementos de respaldo social. A tal efecto, conviene tener en consideración que el terrorismo es un producto político (Crenshaw, 1981; Townshend, 2002; Wieviorka, 2003; López Romo y Fernández Soldevilla, 2018) que responde a una decisión intencional, fruto de la interacción resultante entre actores y estructura social y territorial (Máiz, 2007).

De cualquier forma, conviene precisar que ninguna narrativa refleja o expresa ninguna realidad objetiva. Más bien, todo lo contrario. Cada mirada recogida en este trabajo se integra en una estrategia retórica que responde a cómo debe ser entendida la situación política vasca y la aspiración ideal cuando las armas ya no son un recurso. Algo que indudablemente repercute en los marcos de diagnóstico (causas y problemas de la violencia en el territorio), pronóstico (los más habituales, centrados en ofrecer soluciones) y motivación (que plantean lógicas de acción a los protagonistas) (Snow y Bedford, 1988; Gerhards, 1995).

Sea como fuere, se evita un análisis stricto sensu sobre los tres niveles, optándose por enmarcar las categorías, la relevancia, el alcance y el significado de la violencia política y el conflicto social a partir de una mirada longitudinal de la existencia y evolución de ETA. Lo anterior, desde una perspectiva no exenta de estereotipos, metáforas, falacias, hipérboles o eufemismos (Van Dijk, 2007) que permiten identificar varios aspectos destacables: 1) la importancia de la violencia política y el terrorismo para comprender la situación actual; 2) la falta de apoyo para prolongar esta, prácticamente, desde finales de los 1990; y 3) la necesidades de buscar nuevos repertorios de acción para la consecución de un escenario proclive a la independencia del País Vasco, en donde el conflicto social y político sigue vigente, aun cuando la violencia no sirve medio instrumental para lograr los objetivos que hace seis décadas motivaron el surgimiento de ETA. 
En total se realizaron nueve entrevistas en profundidad ${ }^{2}$ a personas destacadas de la estructura de ETA que siguen mayormente militando en el entorno abertzale, ya sea en el partido político Sortu, que recoge parte del bagaje y capital político de Herri Batasuna, o colaborando con colectivos que promueven la defensa de los presos del grupo terrorista en las prisiones españolas, especialmente en lo referente a la petición de reagruparlos en cárceles de País Vasco y Navarra. De los entrevistados, únicamente dos han cumplido condenas inferiores a los 19 años. Asimismo, el umbral de edades oscila entre los 39 y los 66 años, en tanto que se buscaba disponer de la cobertura más amplia posible. Seis son hombres y tres son mujeres, y su pertenencia obedece a comandos reconocidos de ETA, pero que se obvian para garantizar el anonimato de los entrevistados. Condición esta imprescindible para la realización de unas entrevistas que fueron todas grabadas con el consentimiento expreso de los entrevistados. Claro está, todos ellos fueron seleccionados por su vinculación con comandos destacados para ETA y salvo uno, todos tuvieron responsabilidad en el despliegue de operativos.

Las entrevistas transcurrieron entre el 10 de septiembre y el 2 de noviembre de 2018, pocos meses después del fin de ETA. Se celebraron en Bilbao y Durango y su duración oscila entre los 60 y los 150 minutos. A cada entrevistado se le planteó una entrevista muy similar. Se le preguntó sobre su incorporación a ETA y las motivaciones que la propiciaron, entre la década de los 1980 y los 1990. También se les preguntó sobre la relación entre el mito de pertenecer al grupo terrorista y la realidad del activismo, y respecto de su percepción de cómo el terrorismo era visto por los diferentes anclajes sociales de ETA. Igualmente, las entrevistas abordaron las posibilidades y dificultades reales de lograr la causa separatista, a la vez que problematizaron los aspectos que influyeron en la evolución estratégica de ETA. Además, se plantearon otras cuestiones como el sentido de la violencia y la manera en la que es percibida en la actualidad, en relación con la situación política que atraviesa hoy en día el País Vasco.

Finalmente, ha de destacarse el especial interés por analizar y comprender el punto de vista moral de agentes sociales cuya perspectiva, al no ser la de las víctimas, generalmente sigue estando relegada a un plano marginal por los trabajos académicos. Esto, por ser entendida como una suerte de "mal" que termina siendo condenada ex initio y que se juzga, muy desafortunadamente, como una visión que no merece ser abordada. 


\section{DEL ORIGEN DE ETA HASTA LA TRANSICIÓN}

Mucho se ha escrito sobre los orígenes del terrorismo en general, atendiendo a sus cuestiones ideológicas, identitarias, emocionales, religiosas o culturales (Reinares, 1998; González Calleja, 2002; Corte, 2006; Avilés, Azcona y Re, 2019; Sánchez-Cuenca, 2019), y con respecto a las razones particulares del surgimiento de ETA, referidas al inicio de este artículo. Desde el entorno de la izquierda abertzale, generalmente se identifica el surgimiento de ETA como una respuesta necesaria frente a la agresión del Estado español, lo cual se remonta incluso a las guerras carlistas (Lorenzo, 1998; Egaña, 2017). Ello conecta con la represión franquista, a partir de una construcción discursiva que erige al País Vasco como una de las regiones más golpeadas por la dictadura. Un argumento poco sólido, pues no existen datos que avalen tal condición, como sí sucedió en otros lugares como Andalucía o Extremadura (Espinosa et al., 2010).

Si bien en los años 1990 hubo un importante avance en la contribución académica sobre los orígenes del terrorismo de ETA (Zulaika, 1990; Elorza, 1995), siguió predominando la identificación de factores como la influencia del pensamiento de Sabino Arana, la contribución teórica del tercermundismo o los aspectos propios de la cultura vasca. De acuerdo con Fernández Soldevilla, "se echa en falta un estudio monotemático más extenso que, desde una perspectiva multicausal, tome en cuenta tanto factores externos como internos" (2014: 274).

Más allá de las contribuciones en torno al origen exacto del grupo terrorista (Arteaga, 1971; Letamendía, 1975; De Pablo, 2019), en conformidad con el análisis que propone Mahoney (2018) se aprecian tres momentos diferentes en la etapa inicial de ETA, entre 1958 y 1982: i) un primer momento de estrategia violenta de baja intensidad ${ }^{3}$, hasta 1968; un segundo momento, que compromete las primeras acciones armadas, y que es extensible hasta 1975; y por último, un período que transcurre entre la muerte del dictador Francisco Franco y la llegada al poder del Partido Socialista Obrero Español (PSOE) y que resulta especialmente violento aun cuando coincide, paradójicamente, con la aprobación del Estatuto de Guernica ${ }^{4}$.

Durante su primera década de existencia, el grupo terrorista funcionó bajo una lógica de construcción y consolidación ideológico-discursiva, buscando acumular bases de apoyo (Zirakzadeh, 2002). Huelgas, manifestaciones y actos de propaganda concentraron esta primera 
etapa en donde el recurso de la violencia se encuentra relegado por la falta de medios. No obstante, se estima que a finales de los 1960 la estructura ya había llegado a los 300 integrantes y las fuerzas policiales del régimen franquista habían alcanzado el centenar de operativos (Clark, 1984).

En el año 1968, entre junio y agosto, se producen los dos primeros grandes actos de violencia de ETA, con los asesinatos del Guardia Civil José Antonio Pardines (Fernández Soldevilla y Domínguez, 2018) y el jefe de la Brigada de Investigación Social de San Sebastián, Melitón Manzanas (Domínguez, Alonso y García, 2010). Comienza así un proceso creciente de recurso de la violencia centrado en la estrategia acción-reacción-acción. Es decir, se busca iniciar acciones armadas que motiven la respuesta represora del Estado para, desde ahí, alimentar la idea de un Estado opresor que confiera visibilidad, legitimidad y apoyo al mensaje independentista abertzale. Desde 1968 hasta 1975 se producen 54 acciones armadas que dejan consigo 44 muertes (Mahoney, 2018), siendo destacable el asesinato del Jefe de Gobierno, el almirante Luis Carrero Blanco, en diciembre de 1973. En cualquier caso, la capacidad operativa de ETA seguía siendo incipiente, con apenas 150 integrantes, producto de la fuerte presión militar y policial de los últimos años del franquismo (Clark, 1984).

La muerte del dictador Franco, en noviembre de 1975, abrió un consabido proceso democratizador que supuso para el grupo terrorista un punto de inflexión. El cambio de régimen de gobierno obligaba a un giro discursivo de ETA, en tanto que el cleavage dictadura-liberación quedaba superado. Antes, en la segunda mitad del año 1974, se había producido una importante actividad armada dirigida a policías, coincidente con la Revolución de los Claveles de Portugal y la caída del Régimen de los Coroneles en Grecia. En un contexto como el descrito, en noviembre de 1974, un sector minoritario funda lo que se conoce como ETA-militar (ETAm) y reconoce lo siguiente en su primer manifiesto:

El fascismo se derrumba y es un proceso irreversible a corto plazo (...) pero un nuevo enemigo intenta tomar cuerpo en el aperturismo (...) de cara a la democratización la única posibilidad que ETA tendría hoy día de ofrecer una alternativa política es entrar en posible movimiento o frente popular independentista que coordine a todos los sectores de este pueblo aún sin organizar (...). Por ellos nos separamos del aparato de masas y 
tácticamente limitaremos nuestras funciones al desarrollo de la lucha y a la expresión de nuestras posiciones políticas, según las necesidades del momento (...) apoyando todos los medios a su alcance, incluida la acción armada (Bruni, 1987:217).

Cuando se da este proceso, la mayor parte de la actividad armada se mantiene aún en ETA-político militar (ETA-pm), aunque la ruptura táctica queda patente en los resultados de la segunda parte de la VI Asamblea ${ }^{5}$, cuando en enero de 1975, la todavía facción predominante de la (doble) banda terrorista afirma que:

De cara a la lucha armada, se renuncia definitivamente al esquema de las revoluciones del Tercer Mundo; esto es, a la convicción de que es posible una victoria militar sobre el enemigo tras un enfrentamiento prolongado. Se insiste por el contrario en la importancia de esta para el logro de una victoria política (Bruni, 1987:223).

Esta fractura que termina por extender la vía armada hasta prácticamente 2018. Lo anterior, no en el caso de ETA-pm, la cual finaliza, tras varias escisiones, en la VIII Asamblea de 1986, entendiendo que la clave no reposa en la violencia, sino en la acción política, a través de huelgas, sindicatos y partidos. Entre las dos ETA no existe una diferencia sustancial sobre el concepto de revolución vasca, sino sobre las etapas que esta tiene que recorrer ${ }^{6}$.

A pesar del marco que propiciaba la Ley de Amnistía de $1977^{7}$, el contexto era de clara confrontación de fuerzas: entre 1976 y 1982 se registraron un total de 684 acciones y 892 víctimas (344 mortales) según Global Terrorism Database. Asimismo, el número de efectivos de ETA superó los 1.000 integrantes, triplicando así los registros de 1976 (Llera, Mata e Irvin, 1993), y la causa abertzale llegó a exhibir un nivel de propaganda y fuerza nunca antes visto. El brazo político de ETAm, Herri Batasuna, se convierte en la segunda fuerza política del País Vasco (Sullivan, 1988) y el radicalismo del discurso de ETA encuentra tres factores que favorecen su agitación: i) la causa independentista trasciende el tipo de Gobierno; ii) la vía armada ha de fortalecerse frente a los postulados "tibios" de ETA-pm; y iii) se instrumentaliza la fuerte labor policial, en una segunda fase de la lógica acción-reacción-acción. 


\section{LOS AÑOS 80’ Y 90': CONFRONTACIÓN Y DESGASTE}

El contexto descrito confiere una gran capacidad de respaldo social a la izquierda abertzale más radical y defensora de la vía armada, de modo que la visión del Estado español queda reducida a una mera cuestión de represión, asimilacionismo y maltrato con respecto al destino manifiesto del pueblo vasco ${ }^{8,9}$. Algunos de los entrevistados, que se incorporan a ETA en la década de los ochenta, al ser entrevistados dan buena cuenta de cómo la respuesta frente a los abusos del Estado español se encuentra muy presente. Por ejemplo, uno de los entrevistados, que se integra a ETA en 1980, reconocía cómo "frente a la represión que había en esos años, al final era agua o sal" (Entrevista 1, 26 de septiembre de 2018, Bilbao). Otro de ellos, que entra al grupo terrorista en 1989 apuntaba de qué modo "en un contexto de represión, donde existía una organización armada desde hace años, la única forma política para avanzar era a través de la lucha armada" (Entrevista 2, 27 de septiembre de 2018, Bilbao). Finalmente, un tercero, en términos muy parecidos, y que también pasó a formar parte de ETA en 1989, expresaba de manera ilustrativa que:

ante un nivel represivo, de falta de libertades, te ponen en una situación en la que tú ves la necesidad de responder, no solamente a esa represión individual que puede haber, sino también a una serie de falta de libertades colectivas que, como pueblo, tú consideras que te corresponden. (Entrevista 3, 28 de septiembre de 2018, Bilbao)

Entre 1983 y 1992 es cuando se produce una transformación de la violencia, sobre todo una vez que ETA-pm renuncia a persistir por la vía armada. Para ese entonces Global Terrorism Database contabiliza hasta 866 acciones violentas, que dejan consigo, entre heridos y muertes, 1282 víctimas. Más allá de guardias civiles y policías nacionales, comienzan a ser víctimas de ETA civiles y cargos políticos municipales. Entre 1982 y 1988 son asesinadas 257 personas y la respuesta del Estado, por parte del Gobierno socialista no se hace esperar. Se intensifica como nunca la lucha antiterrorista y se fortalece el aparato normativo a partir de 1984, lo que permite en 1985 detener hasta 900 personas acusadas de vínculos con ETA (Encarnación, 2007). A la vez, tiene lugar la "guerra sucia", a través del funcionamiento de los Grupos Antiterroristas de Liberación (GAL), promocionados por la cúpula del Ministerio del Interior, pero que actuaban contra la legalidad vigente y contra el Estado de derecho. Estos, entre el 16 de octubre de 1983 y el 24 de julio 
de 1987, cometieron 27 asesinatos y otros tantos casos de secuestro y tortura, en los que, en al menos diez casos, acabaron con la vida de personas ajenas a la estructura de ETA.

A esta situación de confrontación la acompaña una suerte de desconfianza mutua que impide cualquier avance en el que fue el primer proceso de diálogo entre ETA y el Gobierno español: el proceso de Argel. Entre el 23 enero y el 23 marzo de 1989 se dio un acercamiento que debía ser el preludio de un diálogo que nunca llegó, dada la falta de madurez para negociar. La respuesta al fracaso de este proceso fue una intensificación de la lucha antiterrorista y el impulso, de parte del propio Felipe González, de medidas como la dispersión carcelaria, cuyo fin era debilitar la estructura que ETA desarrollaba al interior de las instituciones penitenciarias. Tal y como reconoce un destacado antiguo miembro de ETA:

Argel fue el primer reconocimiento en que un gobierno del Estado español quería sentarse a negociar (...) pero fue romper las negociaciones de Argel y empezar la dispersión (...) otra forma de afrontar la cárcel y sobrevivir la cárcel (...) donde ya no estábamos juntos. (Entrevista 1, 26 de septiembre de 2018, Bilbao).

Tres años después de Argel tiene lugar el que para Mahoney (2018) es el golpe que trunca el devenir de ETA como grupo terrorista. Se detiene en Bidart, el 29 de marzo de 1992, una cúpula de ETA formada por José Luis Álvarez Santacristina 'Txelis', José Javier Zabaleta Elósegi ‘Baldo', Francisco Múgica Garmendia 'Paquito' y José Arregi Erostarbe 'Fitti' ${ }^{10}$. Desde entonces, la capacidad operativa de ETA queda notablemente desestructurada, tal y como reconoce el siguiente testimonio de otro miembro de ETA que, precisamente, integra en el grupo terrorista poco después:

Era el año 94. El conflicto estaba en su esplendor y ETA se estaba recomponiendo en su capacidad operativa, de la represión. El Estado español se estaba diversificando, era más metódico, con movimientos más modernos (Entrevista 9, 9 de noviembre de 2018, Bilbao).

Hacia el año 1993, ETA entra en un proceso de debilitamiento continuo en el que se imbrican varios factores. Aparte de una mayor eficacia en la lucha antiterrorista, favorecida por la colaboración con las autorida- 
des francesas (Morán, 1997), hay un elemento clave que es conocido como "socialización del sufrimiento", y que representa un cambio táctico en la forma de actuar de ETA con respecto a sus víctimas ${ }^{11}$.

Así, en la década de los 1990 se producen varios acontecimientos que muestran un tipo de violencia en ETA que empieza a generar recelos en parte de sus bases de apoyo ${ }^{12}$. Por ejemplo, el 26 de julio de 1994 es asesinado el empresario José Manuel Olarte. Tres días después muere el tramoyista César García por un coche-bomba. El 10 de agosto de 1994 es asesinado, tras varios disparos, el albañil José Antonio Díaz. El año siguiente, en diciembre de 1995, se produce un atentado contra un vehículo de la Armada, en el que mueren tres civiles y tres militares. Asimismo, en febrero de 1996 es asesinado, de un tiro en la nuca el concejal socialista, Fernando Mújica y tiroteado en su despacho el catedrático de Historia del Derecho de la Universidad Autónoma de Madrid, Francisco Tomás y Valiente. Igual sucede con el empresario Isidro Usabiaga, el 26 de julio de 1996. Por último, en 1997 son asesinados con un tiro en la nunca el vendedor de bicicletas, Eugenio Olaciregui; el magistrado del Tribunal Supremo, Rafael Martínez; y el empresario y mediador en el secuestro de Emiliano Revilla, Francisco Arratíbel. Igual sucede con los concejales del Partido Popular en Ermua y Rentería, respectivamente, Miguel Ángel Blanco ${ }^{13}$ y José Luis Caso.

Todos ellos tienen un denominador común: la mencionada socialización del sufrimiento por la cual ciudadanos corrientes, y no solo policías y guardias civiles, pasan a ser objeto de los atentados del grupo terrorista (López Romo, 2015; Llera y Leonisio, 2017). Al respecto de esta estrategia, los testimonios de los integrantes de ETA evocan una suerte de inexorabilidad:

La socialización del sufrimiento no se plantea como una simple socialización. Es la socialización del sufrimiento vivido. No del ajeno. De todo cuanto pasan los familiares de la organización y de cuál es el sufrimiento de la gente independentista que no pudo ejercer su derecho de decisión (Entrevista 1, 26 de septiembre de 2018, Bilbao).

Para entender lo anterior, un punto clave pasa por deshumanizar a la víctima y resignificarla como un objetivo político, tal y como reconoce este otro antiguo miembro de ETA: 
(...) a veces intentaba no pensar en ello $y$, como te digo, los principios echarlos por la ventana. Es como una guerra. Todos son objetivos y no te pones a pensar de lo que hay detrás del objetivo (Entrevista 3, 28 de septiembre de 2018, Bilbao).

Pese a todo, la socialización del sufrimiento afectará el alcance de la violencia a partir de mediados de los 1990, al desarrollarse una mayor distancia entre el recurso de la violencia y las bases sociales abertzales. Por ejemplo, si se revisa el Euskobarómetro ${ }^{14}$, es posible observar de qué manera, si a inicios de los 1990 el rechazo total a ETA en la sociedad vasca era de algo más del 40\%, este llega casi al 60\% hacia finales de 1997. Igualmente, en clave retrospectiva, algunos de ETA que pasaron a formar parte del grupo terrorista entre finales de los 1980 y la década de los 1990, coinciden en sus apreciaciones:

Hasta los noventa hay una lucha armada y una aceptación bastante buena, pero a partir de los noventa empieza a haber una diferencia entre la lucha armada y la percepción de la sociedad. (Entrevista 2, 27 de septiembre de 2018, Bilbao).

En la segunda mitad de los noventa hay un cierto desapego. No solo por las acciones que llevamos a cabo, sino por toda la lucha ideológica que había hecho el enemigo con los movimientos de liberación. Cómo prostituyen lo que significa la violencia. Necesitan crear un enemigo, un diablo. Nos presentan como gente loca que empieza a pegar tiros y ahí sí cualquier acción que hacíamos nos empieza a pasar factura (...) Las acciones contra concejales de partidos políticos y otros objetivos, la sociedad no lo entendía. (Entrevista 8, 8 de noviembre de 2018, Bilbao).

A partir de Miguel Ángel Blanco vimos que, por diversas circunstancias y errores de la organización, y de la izquierda abertzale, se fue a una desafección de la gente que no apoyaba o no tenía simpatía no solo a la organización, sino a la izquierda abertzale (Entrevista 9, 9 de noviembre de 2018, Bilbao).

\section{DE LIZARRA-GARAZI A LOYOLA: ANATOMÍA DE UN FIN NEGOCIADO IMPOSIBLE}

El segundo repunte de violencia, que transcurre hasta 1997, conduce a otro escenario de posible negociación: el proceso de Lizarra-Garazi, que inicia con el primer gobierno de José María Aznar. El 12 de septiembre de 1998 se suscribe un pacto entre los partidos nacionalistas, 
llamando a desarrollar un proceso de diálogo y negociación con vistas a cerrar la causa abierta por ETA. En este momento cobra relevancia la experiencia norirlandesa que, a través de los Acuerdos del Viernes Santo, había puesto fin al conflicto con el IRA (Irish Republican Army) (Gurruchaga, 1998). Como plantean algunos de los entrevistados, desde ETA se aprecian diferencias en Lizarra-Garazi con respecto del proceso de Argel, despertando buena acogida en la militancia:

Era la derecha española la que se estaban sentando a negociar contigo. Eran los continuadores del franquismo y tú dices "coño, es otro proceso diferente". Te planteas y dices, pues igual estos en realidad pueden solucionarlo. (Entrevista 1, 26 de septiembre de 2018, Bilbao).

Sin embargo, para otros, este optimismo nuevamente no tardaría en transformarse en frustración con el proceso y la subsiguiente necesidad de retornar a la violencia:

Al principio yo siempre lo vi con mucho optimismo, pero rápidamente ves que no está fructificando nada. Llegó un momento en que no le veía futuro y entonces la ruptura no me pilló por sorpresa (Entrevista 3, 28 de septiembre de 2018, Bilbao).

En cualquier caso, una manera de entender el proceso de Lizarra-Garazi, y descargar responsabilidades sobre "los otros", reposa en entender que el acercamiento fue algo que provino, más bien, del interés de los partidos políticos vascos y no de ETA en sí. Esto es, sucede como si el grupo armado sólo contemplase la solución si previamente el Estado, más allá de la tregua mencionada, aceptaba ciertas precondiciones que en el fondo devenían imposibles.

Aunque la organización hizo sus aportaciones, era un proceso de pueblo. De varios partidos a la vez. (Entrevista 1, 26 de septiembre de 2018, Bilbao).

El de Lizarra, en realidad, fue un proceso más de los partidos políticos que de ETA. (Entrevista 4, 28 de septiembre de 2018, Bilbao).

Al interior de ETA concretamente se culpabiliza al PNV (Partido Nacionalista Vasco) de ser el principal saboteador del proceso, por entrar en un diálogo que le otorgaba popularidad entre la sociedad vasca, 
aun siendo conocedor de que había cuestiones, como la aceptación de la causa separatista, que no podía prosperar, de acuerdo con lo que señalan los siguientes dos antiguos integrantes de ETA entrevistados:

Mientras que la izquierda abertzale siempre ha sido de ruptura, el PNV es un partido de gobierno, de derecha (...) le pedimos algo que no podía dar. Seguramente, aunque no lo hubiéramos hecho, o hubiéramos intentado equilibrar más, hubiera terminado igual. (Entrevista 2, 27 de septiembre de 2018, Bilbao).

Había militancia de la izquierda abertzale ilusionada, pero nos encontramos con un montón de trabas por la militancia del PNV, porque no había toda la fuerza y todo el ánimo que había que tener puesto (...) que tenía más que perder que ganar. (Entrevista 6, 1 de octubre de 2018, Bilbao).

Incluso, otros antiguos militantes de ETA van más allá, al entender que las rencillas entre ETA y el PNV responden a una estrategia de deslegitimación del grupo terrorista, aprovechando el amplio rechazo social que produjeron acciones como el asesinato de Miguel Ángel Blanco. Así, se extiende en el grupo terrorista la convicción de que el PNV, en realidad, quería mostrar a ETA como el factor disruptivo del diálogo, aun sabiendo que las reivindicaciones de fondo de Lizarra-Garazi eran inasumibles:

Lizarra-Garazi tuvo mucho que ver con la muerte de Miguel Ángel Blanco porque el PNV estaba loco e iba a por nosotros. La izquierda abertzale subió (...) y ellos empezaron a creer que Lizarra-Garazi era un premio para la izquierda abertzale y no para ellos. (Entrevista 9, 9 de noviembre de 2018, Bilbao)

A pesar de que ETA en junio de 1998 llega a cerrar un acuerdo con PNV y EA (Eusko Alkartasuna) asumiendo un alto al fuego indefinido, entre junio y septiembre crecen las discrepancias, y para noviembre de 1999 el proceso está completamente roto. ETA lo reconoce el 28 de noviembre de 1999 en el diario Gara, al señalar al PNV y EA como partidos "enemigos de Euskal Herria" y más preocupados por la paz que por la soberanía independentista.

Durante el año que dura el proceso de Lizarra-Garazi, PNV y EA reivindicaron la necesidad de ir más allá en el modelo de transferencia de competencias del Estado autonómico, si bien había una dificultad 
irresoluble respecto de las tres condiciones que exigía ETA: i) negociar los ritmos de la construcción nacional; ii) dejar la puerta abierta a acuerdos con los nacionalistas, si así lo exigía la gobernabilidad y iii) respetar los derechos humanos - lo cual apuntaba claramente a poner fin a la política de dispersión de presos.

Aun con las dificultades de unas exigencias a las que ni el PNV ni EA darán respuesta, Herri Batasuna junto a PNV, EA e IU (Izquierda Unida) suscriben en la Casa de la Cultura de Lizarra un acuerdo que acepta la "naturaleza política del conflicto vasco" y que se refrenda con el alto el fuego unilateral de ETA. Tras lo anterior, tienen lugar las elecciones autonómicas del 25 de octubre de 1998, dando lugar a un panorama político vasco en el que los partidos nacionalistas clásicos y la izquierda abertzale obtuvieron un importante respaldo electoral. El papel de spoiler de ETA no tardaría en aparecer, primero en una reunión entre una delegación de la Moncloa y algunos dirigentes de ETA, en donde queda patente la imposibilidad de la autodeterminación como causa primera del fin de la violencia. Después, en el verano de 1999, ETA exige al gobierno vasco la concurrencia de elecciones inmediatas "para configurar el parlamento de Euskal Herria" y la redacción de una "Constitución soberana".

Lizarra no daba para más y con ello cualquier posibilidad futura de encontrar un proceso en el que contar con cierto respaldo político y social de una izquierda abertzale que cada vez se distanciaba más de la violencia. No obstante, ETA vuelve a la violencia, matando a 46 personas entre 2000 y 2003 y, a la par, la izquierda abertzale termina siendo ilegalizada a tenor de la aprobación de la controvertida Ley de Partidos Políticos ${ }^{15}$ (L.O. 6/2002), abriendo una nueva escalada de tensión, tal y como reconoce el siguiente entrevistado, miembro muy próximo a la cúpula de ETA durante los años 2000:

Cuando Lizarra-Garazi se rompe vuelve la lucha armada. La gente lo vive dentro de la izquierda abertzale con mucha frustración. Por una parte, rabia y un montón de elementos hay ahí, porque no se ha conseguido esa unida. Pero eso pasa factura también a nivel interno y anímico, porque eso quiere decir que ahora habrá un montón de generaciones que van a morir, que van a ser torturadas y encarceladas. (Entrevista 8, 8 de noviembre de 2018, Bilbao).

Bajo este contexto, tres son los factores imprescindibles para entender el proceso de aislamiento de ETA, que se desarrolla desde entonces y que concluye con su disolución en mayo de 2018: i) los atentados de 
11 de marzo de 2004; ii) el distanciamiento de la sociedad civil y la contribución social a la paz que promueven diferentes expresiones que se fortalecen, como Gesto por la Paz o Elkarri; y iii) las consecuencias del último y definitivo esfuerzo por encontrar una solución negociada a través del conocido como Pacto de Loyola. Este, un intento negociador que inicia en 2006 y termina abruptamente con el atentado cometido en la Terminal-4 del Aeropuerto de Barajas, el 30 de diciembre de 2006, que deja consigo dos muertes y una veintena de heridos.

Muy pocos trabajos se han centrado hasta el momento en analizar de qué modo los atentados del 11 de marzo de 2004 contribuyeron a profundizar la imagen negativa de la sociedad española, no sólo con respecto al terrorismo en general, sino con relación a ETA en particular. El atentado de Madrid reivindicado por Al-Qaeda, que dejó consigo 192 víctimas mortales, se integraba con una lógica de terrorismo yihadista que iniciaba ineludiblemente en los atentados del 11 de septiembre de 2001 y que, aparte de Madrid, tuvo consecuencias en otras ciudades como Londres o Bali. Al respecto, las entrevistas con antiguos miembros de ETA muestran cómo el escenario posterior al 11-M trae consigo un nuevo contexto en el que el recurso de la violencia no vuelve a ser percibido igual:

La lectura que yo hice con el 11-M es que nos iba a afectar porque el contexto internacional del terrorismo iba a ser distinto. Todo terrorismo era igual. En mi opinión no es igual. Yo vi que eso nos iba a afectar a la hora de la lucha armada y a que en Euskal Herria hubiera un grupo armado (Entrevista 2, 27 de septiembre de 2018, Bilbao).

El 11-M para los movimientos revolucionarios fue un auténtico desastre (...) ¿cómo haces frente a eso para defender tu planteamiento? (Entrevista 1, 26 de septiembre de 2018, Bilbao).

Es decir, aunque para ETA la justificación del terrorismo no guarda ninguna relación con la causa yihadista - como muestran las entrevistas- al interior de la organización parece existir el convencimiento de que el repertorio de violencia, si ya era difícil de mantener tras los episodios de socialización del sufrimiento de finales de los 1990, más difícil pasó a ser cuando en el imaginario colectivo emergieron imágenes como las de Atocha tras los atentados. 
Viendo lo que pasó con el 11-M dices ¿adónde vamos? ¿No será contraproducente? Pero ante todo eres un militante y estás ahí, aguantando. (Entrevista 7, 7 de noviembre de 2018, Bilbao).

El 11-M fue el principio del final. Antes la lucha armada era un instrumento factible para cumplir un objetivo. Esto lo contaminó todo y fue como un cambio de paradigma de cambio de mentalidad del mundo entero. Que no tuvo ni que haberse utilizado la violencia ni que haber muertos. La sociedad no nos lo iba a permitir. (Entrevista 9, 9 de noviembre de 2018, Bilbao).

El 11-M abría la posibilidad de una situación favorable a endurecer los mecanismos de control, presión y actuación de las Fuerzas y Cuerpos de Seguridad del Estado, tal y como había venido sucediendo desde 1996. Sin embargo, conocedor del debilitamiento irreversible de ETA hacia el año 2004, el recién presidente electo, José Luis Rodríguez Zapatero, entendió que resultaba más propicio abrir un escenario de diálogo con el que poner fin a medio siglo de activismo armado de la organización.

El 11-M es un elemento a tener en cuenta. Yo ya estaba en la clandestinidad. Lo viví con miedo porque sabía que no habíamos sido nosotros, pero lo viví con mucho miedo porque vi que se habían quitado las caretas y la naturaleza franquista y fascista del Estado español. No había duda. Empecinados en señalar que había sido ETA (...) el objetivo era el proyecto independentista. A partir del 11-M lo han aprovechado no solamente en Euskal Herria, sino también a nivel de Estado para recortar derechos en todos los sentidos (Entrevista 8, 8 de noviembre de 2018, Bilbao).

En paralelo al rechazo que motiva el terrorismo, ganan peso específico las movilizaciones por la paz en el País Vasco (Gago, 2017). A las acciones y reivindicaciones de Gesto por la Paz o del Foro de Ermua se suma la contribución de Lokarri - heredera directa de Elkarri -, que aglutina otras fuerzas sociales que hasta ese momento no se encontraban en las dos primeras. Gesto por la Paz había surgido en 1986, aunque desde 1993 gana visibilidad cuando populariza el lazo azul como protesta frente a las acciones de ETA y organiza manifestaciones silenciosas al día siguiente de cada atentado mortal. Por su parte, Lokarri se desarrolla desde 2006 como una movilización ciudadana que incluye entre sus propuestas la revisión de la política de dispersión carcelaria o la necesidad de una negociación política entre ETA y el Gobierno de España. De hecho, Lokarri, con el trabajo destacado de Paul Ríos, fue uno de los promotores de la Conferencia de Aiete 
celebrada el 17 de octubre de 2011, donde personalidades como Kofi Annan, Gerry Adams o Bertie Ahern reclaman el fin de la lucha armada de ETA, que llegará tres días después.

Como se puede destacar de los relatos de algunos entrevistados, ni Gesto por la Paz ni Lokarri fueron iniciativas con buena acogida por parte de ETA, al evocar su rechazo social y poner de manifiesto una realidad en la que, cada vez más, se apreciaba una oposición frontal al recurso de la violencia (Murúa, 2017). Así se recoge en algunos relatos de exintegrantes de ETA, que han tenido una activa militancia política en el entorno abertzale de los últimos años.

En esa época hubo mucha tensión (...) Fueron una herramienta política. Eran los familiares los que recibían atención y los familiares de los encarcelados se les ponían en frente. Me parecía de mucho cinismo y mucha hipocresía. (Entrevista 7, 7 de noviembre de 2018, Bilbao).

Estos movimientos reforzaban la idea de democracia vs violentos, para crear desgaste dentro de la izquierda abertzale (...) había muertos por todas las partes (...) dentro de la izquierda abertzale podemos decir mucho, y ante eso nunca se han posicionado, y sí se han posicionado con las víctimas que ha creado ETA (Entrevista 8, 8 de noviembre de 2018, Bilbao).

El Estado necesitaba tener un instrumento light que tuviera en el oído al partido represor, pero pareciendo un movimiento espontáneo. Fue uno de los instrumentos del Estado, como muchos otros. (Entrevista 9, 9 de noviembre de 2018).

Finalmente, mencionando el Pacto de Loyola cabe destacar que, en inicio, se constituía bajo aparentes condiciones más favorables que en los casos anteriores, pues ETA se hallaba profundamente desacreditada, también por la mayoría de la izquierda abertzale, y con una importante debilidad a nivel orgánico. Así, el 22 de marzo de 2006, anuncia un alto al fuego permanente que comenzaría a hacerse efectivo dos días después. Tres meses más tarde el entonces presidente, José Luis Rodríguez Zapatero, hacía público ante el Congreso de los Diputados el inicio de un proceso de diálogo que no tardaría mucho en quedar truncado. Entre septiembre y noviembre se celebraron hasta once reuniones que, incluso, para el mes de octubre permitieron avanzar en una suerte de preacuerdo formado por ocho puntos que conformaban lo que pasó a conocerse como "Acuerdos de Loyola"16. 
Algunos trabajos relatan los aspectos particulares de este proceso (Eguiguren y Aizpeolea, 2011), en donde si bien se adelantaron importantes avances en Suiza y Noruega, la negociación se desdibujó cuando cambió el equipo negociador y las pretensiones de ETA - integrando Navarra en el reconocimiento requerido al Gobierno. Como resultado, el 30 de diciembre de 2006 se produce un atentado en el aeropuerto de Barajas y, sin capacidad de reconducir el proceso, el Ejecutivo español abandona la vía de la negociación, de manera que ETA retoma a la violencia el 6 de junio de $2007^{17}$. Sin embargo, al respecto, resulta interesante cómo lo anterior, se inscribe para algunos entrevistados más bien en un momento de completa desorientación en cuanto a las pretensiones del grupo terrorista:

Hay un momento de estancamiento en la mesa de negociación y la organización decide hacer la de la T-4. Ahí se rompe todo el proceso. Yo no creo que sea un problema de los interlocutores. Yo creo que es un proceso donde ETA ya no sabe medir las fuerzas reales para conseguir lo que quiere (Entrevista 2, 27 de septiembre de 2018, Bilbao).

Allí (en Loyola) entra el tema de la territorialidad. La apuesta de la izquierda abertzale era un estatuto de autonomía para nuestras cuatro regiones. Vemos que cuando eso se rompe, el punto fundamental es ese: la territorialidad. Empezamos a debatir entre nosotras cómo salimos de eso. Cómo desatascamos ese nudo y cómo vemos ese muro que nos impide seguir en el camino y movemos posiciones para continuar con la lucha armada (Entrevista 8, 8 de noviembre de 2018).

Cuando pasó lo de la T4 estábamos en la cárcel. Nunca antes ETA había hecho un atentado así. Nos quedamos un poco en estado de shock. Intuimos que la organización no tenía capacidad operativa (Entrevista 9, 9 de noviembre de 2018).

\section{EL FIN DE ETA: MIRADAS AL PASADO Y AL FUTURO}

De acuerdo con lo anterior, es de esperar que, desde 2007, el fin de ETA esté más cerca que nunca. Entre ese año y 2011 se contabilizan diez asesinatos, que equivalen a los registros de actividad más bajos de las últimas décadas. La dirigencia del grupo terrorista está fuera de España y la organización apenas cuenta con decenas de integrantes. Se suceden detenciones reiteradas que afectan a un liderazgo joven, inexperto y 
que apenas se mantiene al frente de la estructura unos pocos meses, mostrando una vulnerabilidad que contrasta con la eficiencia de las acciones policiales. Esta situación in crescendo será la que finalmente desemboque en la disolución unilateral de mayo de 2018.

Lejos de pensar que el terrorismo fue un error, en la militancia de ETA que ha cumplido largas condenas es posible encontrar dos rasgos comunes que aparecen en los relatos de los entrevistados: la escasa aprobación al arrepentimiento y la justificación de la violencia en un sentido retrospectivo.

Frente a la reconocida "vía Nanclares ${ }^{18 ", ~ e n ~ l o s ~ u ́ l t i m o s ~ a n ̃ o s ~ g a n o ́ ~}$ popularidad el tema del arrepentimiento a partir del impacto mediático de un exintegrante del comando Santander de ETA: Iñaki Rekarte. Este escribió un libro en 2015 que vendió decenas de miles de ejemplares, Lo difícil es perdonarse a uno mismo, y apareció en varios programas prime time de la televisión española y vasca ${ }^{19}$ (Rekarte, 2015). Sobre tal cuestión, esto expresan algunos antiguos miembros de ETA:

Ante situaciones personales o momentos de crisis personales el arrepentimiento buscas excusas políticas. Es menos respetable si con ello, para librar tu culo, pones en riesgo a alguien o haciendo cosas que van a perjudicar a otros compañeros, al movimiento o a la organización. Eso no lo acepto (Entrevista 6, 1 de octubre de 2018, Bilbao).

No veo adecuado pasar a atacar aquello de lo que has hecho parte. Cuando se ha tenido un papel tan importante. Luego cuando se han puesto a delatar y colaborar con la justicia es repugnante. Es ir en contra de los que han estado contigo (Entrevista 7, 7 de noviembre de 2020).

Unido a lo anterior está el sentimiento de no arrepentimiento y la comprensión de la violencia como un instrumento que ha de normalizarse. Así, y como se puede deducir de los relatos de algunos entrevistados, desde la posición de ETA tradicionalmente se ha negado la necesidad de un perdón recíproco, tal vez motivado por la manera (derrota) en la que se produce su disolución definitiva.

Yo no creo que haya tanto que reconciliar. Ni siquiera tolerar. Sí tienes que aprender a convivir con todo tipo de sensibilidades, pues como lo hemos hecho toda la vida aquí dentro del conflicto (...) Yo no quiero que te vayas 
tú como persona. Yo quiero que se vaya el uniforme que tienes. (Entrevista 3, 28 de septiembre de 2018, Bilbao).

Eso de exigencia de perdón, en ningún caso. Ni si quiera a los alemanes aquí (en alusión a Guernica). Es un tema religioso. Tienes que pedir perdón, aunque no te vas a arrepentir. Me tendrían que explicar muy bien qué función tiene esto (...) “Yo me acuerdo de que, cuando llega el momento de declaración de la lucha armada (...) era echar la firma a una derrota militar. Todo ese proceso yo lo he vivido con tristeza". (Entrevista 4, 28 de septiembre de 2018, Bilbao).

En general, en todos los testimonios de los entrevistados se justifica la existencia de ETA como algo inevitable, gracias a lo cual ha de entenderse tanto la posición de fuerza de la que goza la izquierda abertzale en el País Vasco - en donde actualmente es segunda fuerza política -, como el haber evitado el asimilacionamismo cultural proveniente del nacionalismo español:

La confrontación armada, para la organización, era dejar unos mínimos: la territorialidad y el derecho de autodeterminación (...) sólo por ello la organización tuvo que haber existido (Entrevista 6, 1 de octubre de 2018, Bilbao).

Gracias a ETA se consiguió frenar al nacionalismo español y fortalecer el nivel de conciencia sobre el euskera (Entrevista 7, 7 de noviembre de 2018).

Con ETA hemos evitado la asimilación y ser una comunidad más. Sin la lucha armada, Euskal Herria no sería lo que es hoy. La militancia de la izquierda abertzale es uno de nuestros tesoros (Entrevista 9, 9 de noviembre de 2018).

Así, declaraciones como las anteriores lo que permiten es identificar los argumentos fuerza que legitiman y justifican el uso de la violencia y el terrorismo por parte de ETA, así como su existencia misma, tal y como confirman los siguientes relatos de los entrevistados.

Yo creo que la lucha armada ha sido positiva y trae alternativas en cuanto a mantener una parte importante de este pueblo (Entrevista 2, 27 de septiembre de 2018, Bilbao).

La lucha armada no ha conseguido lo que se planteaba, pero sí de alguna manera ha dejado otra sociedad de la que había antes. Sin ella (esta sociedad) no hubiera existido (Entrevista 3, 28 de septiembre de 2018, Bilbao). 
Yo creo que en relación a la lucha armada, el intentarlo siempre merece la pena (Entrevista 4, 28 de septiembre de 2018, Bilbao).

ETA ha aportado y ha sumado al proceso de liberación. ETA ha aportado en positivo. (Entrevista 7, 7 de noviembre de 2018).

En la actualidad, y como también sucede con los entrevistados para este trabajo, gran parte de la antigua militancia de ETA se encuentra en el partido Sortu. Esta es una pequeña agrupación política que se integra en un proyecto mucho más amplio, heterogéneo y horizontal como es EH Bildu, en donde se concentra el voto mayoritario de la izquierda abertzale. Ello, además, visibiliza un cambio en la cultura política que va más allá de la ruptura con el recurso de la violencia y que en la vieja militancia de ETA relaciona con un cambio generacional que, incluso, pareciera aceptarse con relativa resignación.

Hay que saber leer a esta sociedad que es distinta que la anterior (...) Más confrontación política se tiene que ver como algo natural (...) lo que pasa es que tenemos una sociedad que yo no sé si quiere eso. Yo creo que la sociedad no quiere líos y yo sí creo que hace falta más confrontación y que no todo sea por consenso. (Entrevista 2, 27 de septiembre de 2018, Bilbao).

Cuando salgo de la cárcel me encuentro una sociedad completamente diferente. En el 94 y después, con lo de Lizarra, estaba en ebullición. Todo ha cambiado. Se ha perdido esa tensión en la calle. (Entrevista 9, 9 de noviembre de 2018, Bilbao).

Sea como fuere, lo anterior no debe confundirse con la aspiración de un retorno de la violencia al País Vasco por parte de los entrevistados pues, igualmente, de todas ellas, todo lo contrario, se extrae una percepción generalizada por la que el repertorio del terrorismo como instrumento de disputa no tiene lugar en la actualidad, ni tampoco resulta deseable. Expresado de otro modo, cabría señalar la convicción de que los cauces de cualquier posible conflicto irresoluto pasan, necesariamente, por los cauces estrictamente institucionales y democráticos.

La mentalidad de la sociedad y el apoyo a la lucha armada ha ido disminuyendo (...) Hemos dejado de lado la lucha de una forma y hemos cogido otra (...) Ya todo está disuelto. No queda nada. Y es que no tiene sentido (Entrevista 3, 28 de septiembre de 2018, Bilbao). 
Ahora es el momento de recomponernos y buscar más atenciones. Llegar a una causa común del derecho a decidir y también con el tema de los presos. (Entrevista 9, 9 de noviembre de 2019, Bilbao).

Una situación, no obstante, que no hay que confundir con la no concurrencia de condiciones para la confrontación política, pues es igualmente casi generalizable que en la mayoría de las entrevistas aflora la posición común de entender que las razones que motivaron la aparición de ETA en 1959, en realidad, no han cambiado.

Seguimos igual entre comillas (...) El derecho de autodeterminación, la territorialidad, la amnistía (...) Volver a la lucha armada sería una catástrofe, pero hay que mirar hacia el comunismo libertario. Se debe continuar, aunque hacen falta organizaciones y confrontación. (Entrevista 5, 29 de septiembre de 2018, Durango).

El nudo gordiano no se ha desatado (...) El conflicto político sigue estando. Nunca ha desaparecido (...) La capacidad de la soberanía de este pueblo sigue sin estar en manos de este pueblo y hay 200 personas en la cárcel bajo legislación de excepción que van a estar 40 años en la cárcel y la dispersión sigue vigente. (Entrevista 8, 8 de noviembre de 2018, Bilbao).

\section{CONCLUSIONES}

Resulta importante advertir la ortodoxia con la cual los miembros de ETA entienden el recurso de la violencia. Elementos como la socialización del sufrimiento, la legitimación del terrorismo, el rechazo frontal al arrepentimiento o la falta de necesidades con respecto a medidas de convivencia futura son negados por la militancia de ETA entrevistada en este artículo.

Tímidamente se admiten errores, aunque es el cambio de estrategia armada, las transformaciones de la sociedad civil, las afectaciones externas como los atentados del 11-M o las transformaciones de la sociedad vasca, los fundamentos que más importancia tienen a la hora de enmarcar la evolución y transformación de ETA. De esta manera, es como si en todo momento existiera una auto-exculpación de los entrevistados a la hora de hacer repaso crítico al papel de ETA en la situación política vasca y española. 
Todos los entrevistados descartan unánimemente la posibilidad de retornar a la violencia, si bien destacan que los aspectos fundamentales que motivaron la aparición de ETA siguen vigentes en España y en la sociedad vasca. Sociedad vasca de la que consideran que es gracias al grupo terrorista que la izquierda abertzale es segunda fuerza política en la actualidad. De la misma manera, para ETA la sociedad vasca es responsable de su menor capacidad movilizadora, siendo instrumentalizada como "títere" político cuando aparecieron las movilizaciones de Gesto por la Paz o Elkarri. Algo, no obstante, que contrasta con un relato excesivamente condescendiente con un grupo terrorista que desde finales de los años noventa pasa a ocupar un espacio de apoyo cada vez más reducido, tal y como señala la mayoría de la literatura especializada.

Pese a que el legado de ETA ocupa un reducto marginal del espacio político-partidista vasco, cosa distinta es el nivel de influencia que puede obtener en aquellos escenarios en donde la presencia y el apoyo a ETA fueron notables hasta hace tres décadas. Allí es dónde la intensidad de un conflicto irresoluto para ETA puede ser mayor y en donde se encuentran las mayores amenazas para la convivencia y la normalidad democrática. Igualmente, otros elementos como las movilizaciones sobre la dispersión de presos, los homenajes a miembros de ETA que cumplen condena o la disputa por el controvertido relato, hacen que, aunque el fin de ETA es un hecho ineludible, siga siendo especialmente conflictivo e irresoluto para parte del imaginario colectivo vasco y español.

En definitiva, sigue siendo un objeto de estudio por analizar la manera en que, al interior de ETA, se reconstruye el sentido ideológico y el recurso de la violencia política para inscribirlo en la actualidad. Este no es más que un aporte exploratorio que necesitará de otros trabajos de investigación futuros con los que recurrir a miradas más concretas, por ejemplo, respecto de estudios inter-generacionales entre los exintegrantes de ETA, o de acuerdo a miradas transversales con relación a otros grupos y formaciones que, más allá de ETA, también legitimaron el uso de la violencia política contra el Estado y la sociedad. 


\section{NOTAS}

1. Acción policial contra la dirigencia de ETA que posteriormente será abordado en este trabajo.

2. Como es de esperar, se podrían discernir más conjuntos discursivos que los que hemos señalado sobre este objeto de estudio, los que bien pueden motivar trabajos futuros.

3. Las primeras tres bombas de ETA se dan en el otoño de 1959. En 1961, su primer atentado es reivindicado. En 1963, la primera paliza. Y en 1965 el primer atraco. De este modo, a partir de 1967 es que se inicia la intensificación de atracos, bombas y tiroteos (Fernández Soldevilla, 2018).

4. El Estatuto de Guernica o Estatuto de Autonomía del País Vasco, aprobado en octubre 1979, es la norma de referencia por la que, producto de su nacionalidad cultural, el País Vasco dispuso de un reconocido autogobierno que le permitía constituirse como Comunidad Autónoma (García de las Heras, 2018).

5. ETA funcionó orgánicamente en torno a asambleas. En la IV Asamblea, celebrada en 1965, se identifican tres corrientes: los "culturalistas", que representaban al sector más vasquista; los "obreristas", que anteponían la lucha de clases; y los "tercermundistas", que imbricaban independencia vasca y liberación nacional. La V Asamblea transcurre en dos momentos, diciembre de 1966 y marzo de 1967. Las divergencias entre "obreristas" y "nacionalistas" alimenta la primera escisión del grupo terrorista. La VI Asamblea comienza en agosto de 1970 y aviva nuevas tensiones entre el sector más militarista y otro, mayoritario, de impronta obrerista, que defiende que la lucha armada ha de supeditarse a la lucha política. Así, los militaristas no aceptan las resoluciones de la Asamblea y pasan a ser conocidos como ETA V. Esta facción de ETA, minoritaria, se hace con el control del grupo terrorista y organiza la VI Asamblea, en la cual, se produce la definitiva ruptura entre la vía militar y la político-militar.

6. Zutik, 65. Septiembre de 1975.

7. El 9 de diciembre de 1977 salió de la cárcel el último preso de ETA que quedaba: Fran Aldanondo. La Ley de Amnistía ofrecía una tabula rasa de excarcelación para delitos políticos, incluso de sedición y rebelión, de los que se beneficiaron, entre otros, los miembros de ETA. Se entendía que así se facilitaba la construcción de las bases del nuevo sistema democrático.

8. En 1980, Herri Batasuna se convierte en segunda fuerza política del País Vasco y en 1986 consigue su mejor resultado electoral en unas elecciones generales.

9. La aprobación de la Ley de Amnistía es fundamental para entender el ciclo movilizador durante los primeros compases de la Transición. Los debates internos que culminan en la escisión de ETA están enmarcados en esta coyuntura: el descenso de las movilizaciones obliga a adoptar nuevas orientaciones ajustadas a un nuevo contexto. Un texto muy interesante sobre esta cuestión: Sánchez-Cuenca y Aguilar (2009).

10. Se trata del primer gran resultado de la cooperación con las autoridades francesas. Estas son inicialmente reticentes a pesar de la sintonía de los ejecutivos socialistas (González/ Miterrand) y sólo accederieron a dicha cooperación tras comprobar que las acciones de ETA también afectan intereses franceses (incluyendo la ubicación de santuarios en territorio galo). Algunos como Domínguez (2017) señalan que si no es por Mikel Albisu ("Mikel Antza") y Gracia Arregi ("Iñaki de Rentería”), ETA difícilmente se habría recompuesto. 
Jerónimo Ríos Sierra

11. Desde 1994, como consecuencia de los pactos políticos y la mayor oposición a las acciones armadas de ETA por parte de la sociedad vasca, surge un debate dentro de la izquierda abertzale sobre cuál debe ser la estrategia que adoptar. Al interior del grupo terrorista se presentaron dos ponencias: Iratzar, que abogaba por flexibilizar las posturas y primar la acción política siguiendo las tendencias sociales del momento; y ponencia Oldartzen, que defendía la denominada socialización del sufrimiento. Esta ponencia, que fue la que acabo imponiéndose, suponía una llamada a la acumulación de fuerzas, a la apertura de nuevos frentes de lucha y a la intensificación y diversificación de las acciones violentas. En febrero de 1995, tras la participación en 211 asambleas locales de Navarra y País Vasco, y de 5.322 militantes de Herri Batasuna, Oldartzen se imponía como línea oficialista de ETA al sector crítico de Iratzar, con un respaldo del 71,23\%.

12. El atentado de Hipercor, en junio de 1987 (21 víctimas mortales y 45 heridos), marca el punto de inflexión del posterior declive en el apoyo social que respalda a ETA.

13. Moreno (2019) considera que este hecho marca el punto de inflexión clave en la movilización contra el terrorismo.

14. Véase: https://www.ehu.eus/es/web/euskobarometro/serieak.

15. El 28 de marzo de 2003 se notificó la ilegalización de Herri Batasuna, Euskal Herritarrok y Batasuna, arguyéndose su proximidad a ETA y falta de rechazo expreso a la violencia. Esto se extendería a otras formaciones como Acción Nacionalista Vasca, Partido Comunista de las Tierras Vascas y los grupos parlamentarios Sozialista Abertzaleak y Nafarroako Sozialista Abertzaleak.

16. Entre esos puntos destaca: i) reconocimiento de la identidad vasca; ii) respeto del Estado a las decisiones de la sociedad vasca; iii) reconocimiento del euskera como lengua oficial de País Vasco y Navarra; iv) creación de un órgano interinstitucional entre País Vasco y Navarra; v) creación de una Eurorregión amparada por la Unión Europea; vi) ratificación por referéndum; vii) creación de un calendario de trabajo y viii) acuerdo marco a depositar en el Vaticano.

17. Conviene precisar que este atentado empuja a ciertos sectores de la izquierda abertzale a hacer autocrítica, como ya había hecho en 2001 Aralar. De hecho, es ahí cuando líderes de la Izquierda Abertzale como Rufi Etxebarría replantean junto a Otegi la estrategia al estilo norirlandés de avanzar hacia la paz.

18. La vía Nanclares - en relación con la cárcel alavesa de Nanclares de Oca - es como se reconoce al proceso de reinserción para integrantes de ETA que están en prisión. Implica diferentes beneficios carcelarios siempre que se den unas condiciones: i) distanciamiento del entorno de ETA; ii) acatamiento de la política penitenciaria; iii) abandono del colectivo de presos; iv) renuncia pública y expresa a ETA; v) petición de perdón y reparación a las víctimas; y vi) colaboración con la Justicia en la lucha antiterrorista. Véase: Rivera y Mateo (2019).

19. Conviene señalar que en ETA existen precedentes ilustrativos del rechazo al arrepentimiento, tal y como muestran los asesinatos de exintegrantes como Miguel Francisco Solaun (1984) o Dolores González Catarain, "Yoyes" (1986). 


\section{REFERENCIAS}

ALCEDO, Miren. (1996), Militar en ETA: historias de vida y muerte. San Sebastián: Haranburu.

ALONSO, Rogelio. (2018), La derrota del vencedor. La política antiterrorista del final de ETA. Madrid: Alianza.

ARTEAGA, Federico. (1971), ETA y el proceso de Burgos. Madrid: Aguado.

AVILÉS, Juan; AZCONA, José Manuel;RE, Matteo. (2019), Después del 68: la deriva terrorista en Occidente. Madrid: Sílex.

BRUNI, Luigi. (1987), ETA. Historia política de una lucha armada. Bilbao: Txalaparta.

BULLAIN, Iñigo. (2011), Revolucionarismo patriótico. El Movimiento de Liberación Nacional Vasco. Origen, ideología, estrategia y organización. Madrid: Tecnos.

CASQUETE, Jesús. (2009), En nombre de Euskal Herria. La religión política del nacionalismo vasco radical. Madrid: Tecnos.

CLARK, Robert. (1984), The Basque Insurgents: ETA 1952-1980. Madison: The University of Wisconsin Press.

CORTE, Luís de la. (2006), La lógica del terrorismo. Madrid: Alianza.

CRENSHAW, Martha. (1981), "The Causes of Terrorism”. Comparative Politics, vol. 13, n 4 , pp. 379-399.

DE PABLO, Santiago. (2017), Creadores de sombras. Madrid: Tecnos.

(2019), “Julio de 1959: el nacimiento de ETA". Historia Actual Online, vol. 48, nº 1, pp. $45-59$.

DE PABLO, Santiago; MOTA, David; LÓPEZ DE MATURANA, Virginia. (2019), Testigo de cargo: la historia de ETA y sus víctimas en televisión. Bilbao: Beta III Milenio.

DOMÍNGUEZ, Florencio. (2012), La agonía de ETA. Una investigación inédita sobre los últimos días de la banda. Madrid: La Esfera de los Libros.

. (2000), “La violencia nacionalista de ETA”. En: J. Santos (ed.), Violencia política en la España del siglo XX. Madrid: Taurus, pp. 327-361.

; ALONSO, Rogelio; GARCÍA, Marcos. (2010), Vidas rotas: la historia de los hombres, las mujeres y los niños víctimas de ETA. Madrid: Espasa.

DOMÍNGUEZ. Florencio. (2017), "Las claves de la derrota de ETA". Informe del Centro Memorial de las Victimas del Terrorismo, $\mathrm{n}^{\circ} 3$, pp. 1-62.

DUHART, Philippe. (2017), "From armed group to movement: armed struggle and movement formation in Northern Ireland and the Basque Country". Social Movements Studies, vol. $16, \mathrm{n}^{\circ} 5$, pp. 535-548.

. (2019), "Talking with terrorists, talking with governments: insurgent perspectives on legitimisation and engagement". Critical Studies on Terrorism, vol. 12, n 3, pp. 395-415.

EGAÑA, Iñaki. (2017), Breve historia de ETA. Orkoien: Txalaparta. 
EGAÑA. Iñaki y GIACOPUZZI, Giovanni. (2012), La construcción del enemigo. ETA a la vista de España. Tafalla: Txalaparta.

EGUIGUREN, Jesús; AIZPEOLEA, Luís. (2011), ETA: las claves de la paz. Memorias de un negociador. Madrid: Aguilar.

ELORZA, Antonio. (1995), La religión política. "El nacionalismo sabiniano" y otros ensayos sobre nacionalismo e integrismo. San Sebastián: R\&B.

. (2000), La historia de ETA. Madrid: Temas de Hoy.

ENCARNACIÓN, Omar. (2007), “Democracy and Dirty Wars in Spain”. Human Rights Quarterly, vol. 29, nº 4, pp. 950-972.

ESPINOSA, Francisco (coord.). (2010), Violencia roja y azul: España, 1936-1950. Madrid: Crítica.

FERNÁNDEZ SOLDEVILLA, Gaizca. (2014), “El simple arte de matar. Orígenes de la violencia terrorista en el País Vasco". Historia y Política, vol. 32, pp. 271-298.

. (2016), La voluntad del gudari. Génesis y metástasis de la violencia de ETA. Madrid: Tecnos.

FERNÁNDEZ SOLDEVILLA, Gaizca; DOMÍNGUEZ, Florencio. (2018), Pardines. Cuando ETA empezó a matar. Madrid: Tecnos.

FERNÁNDEZ SOLDEVILLA, Gaizka. (2013), Héroes, heterodoxos y traidores. Historia de Euskadiko Ezquerra (1974-1994). Madrid: Tecnos.

GAGO, Egoitz. (2017), La contribución social a la paz de Euskadi. Madrid: La Catarata.

GARCÍA DE LAS HERAS, Mariano. (2018), “Procesos transicionales y violencia política: la continuidad de la lucha armada de ETA (1977-1982)". Revista de Investigaciones Políticas y Sociológicas, vol. $17, \mathrm{n}^{\circ} 2$, pp. 87-112.

GARMENDIA, José María. (1996), Historia de ETA. San Sebastián: Haramburu.

GERHARDS, Jürgen. (1995), “Framing dimensions and framing strategies: contrasting idealand real-type frames". Social Sciences Information, vol. 34, $\mathrm{n}^{\circ}$ 2, pp. 225-.

GLOBAL TERRORISM DATABASE (s.f.). Disponible en: https://www.start.umd.edu/gtd/. Consultado el 14/10/2019.

GONZÁLEZ CALLEJA, Eduardo. (2002), Políticas del miedo. Un balance del terrorismo en Europa. Madrid: Biblioteca Nueva.

GURRUCHAGA, Iñaki. (1998), El modelo irlandés: historia secreta de un proceso de paz. Barcelona: Península.

IBARRA, Pedro. (1989), La evolución estratégica de ETA: De la guerra revolucionaria hasta después de la tregua. San Sebastián: Kriselu.

; AHEDO, Igor. (2004), “De la centralidad a los márgenes: un viaje en la historia de ETA". En: J. Agirreazkuenaga (ed.), Historia de Euskal Herria: Historia General de los Vascos, vol. 6. San Sebastián: Lur Argitaletxea, pp. 361-378.

IZQUIERDO, José María; RODRÍGUEZ AIZPELOA, Luís. (2017), El fin de ETA. Así derrotó la democracia al terror. Barcelona: Espasa. 
JIMÉNEZ, María; MARRODÁN, Javier. (2019), Heridos y olvidados. Los supervivientes del terrorismo en España. Madrid: La Esfera de los Libros.

LETAMENDÍA, Francisco. (1975), Historia de Euskadi: el nacionalismo vasco y ETA. París: Ruedo Ibérico.

(1994), Historia del nacionalismo vasco y de ETA. San Sebastián: R\&B.

LLERA, Francisco; LEONISIO, Rafael. (2017), “La estrategia del miedo. ETA y la espiral del silencio en el País Vasco". Informe del Centro Memorial de las Víctimas del Terrorismo, $\mathrm{n}^{\mathrm{o}}$. 1, pp. 1-55.

LLERA, Francisco; MATA, José; IRVIN, Cynthia. (1993), “ETA: From Secret Army to Social Movement - The Post-Franco Schism of the Basque Nationalist Movement". Terrorism and Political Violence, vol. 5, nº 3, pp. 106-134.

LÓPEZ ADÁN, Emilio. (1976), El nacionalismo vasco y clases sociales. Estella: Txertoa.

LÓPEZ ROMO, Raúl. (2015), Informe Foronda. Los efectos del terrorismo en la sociedad vasca. Madrid: La Catarata.

. (2018), Memorias del terrorismo en España. Madrid: La Catarata.

;FERNÁNDEZ SOLDEVILLA, Gaizca. (2018), “Deuda de sangre. La visión del pasado de ETA y el IRA". Aportes, vol. 97, n 2, pp. 267-294.

LORENZO, Josemari. (1998), “Los motivos de la violencia en la historia vasca contemporánea". Vasconia, no 26, pp. 271-276.

MAHONEY, Charles. (2018), "End of the cycle: assessing ETA's strategies of terrorism". Small Wars \& Insurgencies, vol. 29, nº 5-6, pp. 916-940.

MÁIZ, Ramón. (2007), “México: la Guerra de las palabras, marcos interpretativos y estrategias identitarias en el discurso político del EZLN (1994-)". En: S. Martí (ed.), Pueblos indígenas y política en América Latina. El reconocimiento de sus derechos y el impacto de sus demandas a inicios del siglo XXI. Barcelona: Fundación CIDOB, pp. 393-434.

MEES, Ludger. (2019), The Basque Contention: Ethnicity, Politics, Violence. London: Routledge.

MORÁN, Sagrario. (1997), ETA: entre España y Francia. Madrid: Universidad Complutense de Madrid.

MORENO, Irene. (2019), Gestos contra el miedo. Manifestaciones contra el terrorismo en el País Vasco (1975-2013). Madrid: Tecnos.

MURÚA, Imanol. (2017), “No more bullets for ETA: the loss of internal support as a key factor in the end of the Basque group's campaign". Critical Studies on Terrorism, vol. 10, $\mathrm{n}^{\circ}$ 2, pp. 93-114.

PORTELA, Edurne. (2016), El eco de los disparos: cultura y memoria de la violencia. Barcelona: Galaxia Gutenberg.

PROKKOLA, Eeva-Kaisa. (2014), “Using Narrativity as Methodological Tool”. ACME: An International E-Journal for Critical Geographies, vol. 13, $\mathrm{n}^{\circ}$ 3, pp. 442-.

REINARES, Fernando. (1998), Terrorismo y antiterrorismo. Barcelona: Paidós. 
Jerónimo Ríos Sierra

(2011), Patriotas de la muerte: por qué han militado en ETA y cuándo abandonan. Madrid: Taurus.

REKARTE, Iñaki. (2015), Lo difícil es perdonarse a uno mismo: matar en nombre de ETA y arrepentirse por amor. Barcelona: Península.

RIVERA, Antonio. (2018), “Una paz donde no hubo Guerra. El final del terrorismo en el País Vasco". Vínculos de Historia, nº 7, pp. 115-131.

; MATEO, Eduardo. (2019), Víctimas y política penitenciaria. Claves, experiencias y retos de futuro. Madrid: La Catarata.

RODRÍGUEZ AIZPEOLEA, Luis. (2013), Los entresijos del fin de ETA. Un intento de recuperar una historia manipulada. Madrid: La Catarata.

SÁNCHEZ-CUENCA, Ignacio. (2011), ETA contra el Estado. Las estrategias del terrorismo. Barcelona: Tusquets.

(2019), The Historical Roots of Political Violence. Cambridge: Cambridge University Press.

SÁNCHEZ-CUENCA, Ignacio; AGUILAR, Paloma. (2009), “Terrorist violence and popular mobilization: the case of the Spanish transition to democracy". Politics $\mathcal{E}$ Society, vol. $37, \mathrm{n}^{\circ} 3$, pp. $428-453$.

SILVA, Lorenzo, SÁNCHEZ, Manuel y ARALUCE, Gonzalo. (2017), Sangre, sudor y memoria. La Guardia Civil contra ETA. Barcelona: Península.

SNOW, David; BENFORD, Robert. (1988), "Ideology, frame resonance and mobilization". En: B. Klandermans; H. Kriesi; S. Tarrow (eds.), From structure to action: comparing social movement research across cultures. Greenwich: JAI Press, pp. 197-218.

SOTO, Iñaki. (2018), La última entrevista con la dirección de ETA. Tafalla: Txalaparta/Gara.

SULLIVAN, John. (1988), ETA and Basque Nationalism: The Fight for Euskadi, 1890-1986. Nueva York: Routledge.

TOWNSHEND, Charles. (2002), Terrorism: A Very Short Introduction. Oxford: Oxford University Press.

VAN DIJK, Teun. (2007), Racismo y discurso en América Latina. Barcelona: Gedisa.

WIEVIORKA, Michel. (2003), The Making of Terrorism. Chicago: University of Chicago Press.

ZABALO, Julen; SARATXO, Mikel. (2015), “ETA ceasefire: Armed struggle vs. political practice in Basque nationalism". Ethnicities, vol. 15, no 3, pp. 362-384.

ZIRAKZADEH, Cyrus. (2002), "From Revolutionary Dreams to Organizational Fragmentation: Disputes over Violence within ETA and Sendero Luminoso". Terrorism and Political Violence, vol. $14, \mathrm{n}^{\circ} 4$, pp. 66-92.

ZULAIKA, Joseba. (1990), Violencia vasca. Metáfora y sacramento. Madrid: Nerea.

; MURÚA, Imanol. (2017), "How terrorism ends - and does not end: the Basque case". Critical Studies on Terrorism, vol. 10, $\mathrm{n}^{\circ} 2$, pp. 338-356. 


\section{RESUMO}

Terrorismo, Legitimidade e Militância: Uma Análise Discursiva sobre ETA

O trabalho seguinte analisa a evolução e o alcance da violência política e o terrorismo de ETA a partir de entrevistas em profundidade feitas a membros proeminentes da organização terrorista. Procuram-se abordar os instrumentos discursivos sobre a legitimação da violência e sua compreensão na evolução de décadas de terrorismo. Entre outros, também serão analisados os fatores que debilitaram o respaldo social de ETA e se explora sobre a interpretação da violência política não só em retrospectiva, mas também visando ao futuro político do País Vasco. Em conclusão, é possível encontrar uma ortodoxia profunda na aceitação e legitimação do uso da violência, embora com certas contradições e sentimento de amargura. Assim, é um contributo importante para uma literatura especializada que, na sua maioria, ignora a história dos terroristas e que, quando a incorpora, o faz a partir de posições de arrependimento ou de uma proximidade excessiva com a estrutura da ETA.

Palavras-chave: ETA, narrativas, País Vasco, terrorismo, violência política.

\section{ABSTRACT \\ Terrorism, Legitimacy and Militancy: A Discursive Analysis on ETA}

The following article analyzes the evolution and scope of ETA's political violence and terrorism based on in-depth interviews with prominent members of the terrorist organization. It seeks to address the discursive instruments on the legitimization of violence and its understanding in the evolution of decades of terrorism. Among others, this work also analyzes the factors that weakened ETA's social support. Finally, these pages explore the retrospective interpretation of violence and the future political scenarios of the Basque Country. In conclusion, it is possible to find a deep orthodoxy when it comes to accepting and legitimizing the use of violence, although with certain contradictions and feeling of bitterness. Thus, it is an important contribution to a specialized literature that mostly ignores the terrorist narratives and that when it incorporates it, it does so from positions of regret or from an excessive proximity to the structure of ETA.

Keywords: ETA; narratives; Basque Country; terrorism; political violence 


\section{RÉSUMÉ}

Terrorisme, Légitimité et Militantisme: Une Analyse Discursive sur l'ETA

Le travail suivant analyse l'évolution et la portée de la violence politique et du terrorisme de l'ETA sur la base d'entretiens approfondis avec des membres éminents de l'organisation terroriste. Il cherche à aborder les instruments discursifs sur la légitimation de la violence et sa compréhension dans l'évolution de décennies de terrorisme. Entre autres, ce travail analyse également les facteurs qui ont affaibli le soutien social de l'ETA. Enfin, ces pages explorent l'interprétation rétrospective de la violence et des futurs scénarios politiques du Pays Basque. En conclusion, il y a une profonde orthodoxie à l'acceptation et légitimation de la violence, malgré certaines contradictions et un sentiment d'amertume. L'article est donc une contribution importante à la littérature spécialisée qui, pour l'essentiel, ignore l'histoire des terroristes, ou alors la considère puisqu'une position excessivement proche de la structure de l'ETA ou comme expression de regret.

Mots-clés: ETA; récits, Pays Basque; terrorisme; violence politique

\section{RESUMEN}

Terrorismo, Legitimidad y Militancia: Un Análisis Discursivo sobre ETA

El siguiente artículo analiza la evolución y el alcance de la violencia política y el terrorismo de ETA a partir de entrevistas en profundidad realizadas a destacados miembros de la organización terrorista. Se busca abordar los instrumentos discursivos sobre la legitimación de la violencia y su comprensión en la evolución de décadas de terrorismo. Entre otros, también se analizan también los factores que debilitaron el respaldo social de ETA y se explora sobre la interpretación de la violencia política no sólo en retrospectiva, sino también con vistas al futuro político del País Vasco. En conclusión, es posible encontrar una profunda ortodoxia a la hora de aceptar y legitimar el uso de la violencia, aunque con ciertas contradicciones y sensación de amargura. Así, se trata de una contribución importante para una literatura especializada que mayormente obvia el relato de los terroristas y que cuando lo incorpora, lo hace desde posiciones de arrepentimiento o desde una excesiva proximidad a la estructura de ETA.

Palabras clave: ETA; narrativas; País Vasco; terrorismo; violencia política 